\title{
O JOGO COMO RECURSO PEDAGÓGICO NO ENSINO DE CIÊNCIAS: UMA PROPOSTA PARA O ENSINO E APRENDIZAGEM DA BIODIVERSIDADE
}

THE GAME AS A PEDAGOGICAL RESOURCE IN SCIENCE EDUCATION: A PROPOSAL FOR THE TEACHING AND LEARNING OF BIODIVERSITY

EL JUEGO COMO RECURSO PEDAGÓGICO EN LA ENSEÑANZA DE CIENCIAS: UNA PROPUESTA PARA EL ENSEÑO Y APRENDIZAJE DE LA BIODIVERSIDAD

Danielle Schultz

\section{(iD) 9}

Licenciada em Educação do

Campo (UFV)

danielle_schultz2013@hotmail.co

$\underline{\mathrm{m}}$

\section{Aline Aparecida Teixeira \\ da Silva \\ (iD) 9}

Mestrado Profissional em Química (UFV)

Professora no Colégio Coeducar em Viçosa (MG)

alineapteixeiras@yahoo.com.br

\section{Cristiane Lopes Rocha de Oliveira \\ iD 9}

Mestrado em Química (UFJF)

Professora no Departamento de

Educação da Universidade Federal de Viçosa (UFV)

cristiane.oliveira@ufv.br

\begin{abstract}
Resumo
A ludicidade em ambiente escolar favorece o desenvolvimento de ações investigativas e criativas no processo de ensino e aprendizagem. Este artigo apresenta o jogo didático como estratégia pedagógica para o ensino de Ciências. O jogo de tabuleiro denominado: "Guardiões da Biodiversidade", com direcionamento ao bioma da Mata Atlântica, foi confeccionado com recursos de baixo custo e de fácil acessibilidade. Selecionou-se, como público-alvo, a turma do $7^{\circ}$ ano dos anos finais do Ensino Fundamental, realizando o estudo em uma escola pública urbana e regular da Zona da Mata Mineira (MG), em 2019. Trata-se, assim, de uma pesquisa de caráter qualitativo e as informações obtidas foram organizadas a partir da análise descritiva. Atesta-se que o jogo didático constitui uma alternativa viável para construção de conhecimentos no ensino de Ciências de forma interdisciplinar, ao estimular as relações de cooperação e socialização entre educador-educando e educandos-educandos. Palavras-chave: Jogo Didático. Ensino e Aprendizagem. Ensino de Ciências. Biodiversidade.
\end{abstract}

Recebido em: 14 de março de 2021. Aprovado em: 1 de junho de 2021.

Como citar esse artigo (ABNT):

SCHULTZ Danielle; SILVA, Aline Aparecida Teixeira da; OLIVEIRA, Cristiane Lopes Rocha de. O jogo como recurso pedagógico no Ensino de Ciências: uma proposta para o ensino e aprendizagem da Biodiversidade. Revista Prática Docente, v. 6, n. 2, e036, 2021.

http://doi.org/10.23926/RPD.2021.v6.n2.e036.id1047 


\section{Abstract}

Playfulness in the school environment favors the development of investigative and creative actions in the teaching and learning process. This article presents the didactic game of pedagogical strategy for the teaching of Sciences. The board game called: "Guardians of Biodiversity", aimed at the Atlantic Forest biome, was made with low-cost and easily accessible resources. The target group was the class of the 7th year of the final years of elementary school, carrying out the study in an urban and regular public school in the Zona da Mata Mineira (MG), in 2019. It is, therefore, a qualitative research and the information obtained was organized based on descriptive analysis. It is evidenced that the didactic game constitutes a viable alternative for the construction of knowledge in Science teaching in an interdisciplinary way, by stimulating the cooperative and socialization relations between educator-learner and learner-learners.

Keywords: Didactic Game. Teaching and learning. Science teaching. Biodiversity.

\section{Resumen}

El carácter lúdico en el medio escolar es muy benéfico al desarrollo de acciones investigativas y creativas en el proceso de enseñanza y aprendizaje. Este artículo presenta el juego didáctico como una táctica pedagógica para la enseñanza de Ciencias. El juego de tablero nombrado "Guardiões da Biodiversidade" que es direccionado al bioma de la Mata Atlántica, fue hecho con recursos de bajo costo y fácil accesibilidad. El público objeto elegido fue un grupo del $7^{\circ}$ año de los años finales de la enseñanza básica. El estudio fue realizado en una escuela pública, urbana y regular de la Zona da Mata Mineira (MG), en 2019. De esta manera, es una investigación con carácter cualitativo y la información obtenida se organizó a partir de un análisis descriptivo. Se asegura que el juego didáctico es una opción viable para la construcción de conocimientos en la enseñanza de Ciencias de manera interdisciplinar, al inducir las relaciones de cooperación y socialización entre educadoreducando y educandos-educandos.

Palabras Clave: Juego didáctico. Enseñanza y Aprendizaje. Enseñanza de Ciencias. Biodiversidad. 


\section{INTRODUÇÃo}

O ensino de Ciências, como apontam Cachapuz et al. (2011), Chassot (2010), Carvalho e Gil-Pérez (2011), deve propiciar aos alunos a compreensão da natureza como um processo dinâmico, despertando questionamentos e investigações, de forma crítica e construtiva, além de permitir que aspectos científicos sejam interligados às dimensões sociais, econômicas, políticas, culturais e ambientais.

A Base Nacional Comum Curricular (BNCC) apresenta a importância do Ensino de Ciências por possibilitar aos educandos o desenvolvimento de uma visão consciente acerca do mundo, e ainda oferecer escolhas e intervenções que favoreçam o exercício da cidadania (BRASIL, 2017).

Nessa perspectiva, a contextualização dos saberes com as realidades dos estudantes é fundamental, destacando-se o acesso aos conhecimentos e às competências relacionadas aos assuntos científicos e tecnológicos, o que, por sua vez, oferece subsídios para reflexão de problemas reais presentes na sociedade (SANTOS, 2007; XAVIER, FLÔR, 2015).

Cunha (2012) e Silva, Catão e Silva (2020) pontuam o desafio dos professores de Ciências em desenvolverem estratégias de ensino que relacionem os saberes prévios dos discentes e os saberes científicos, pois os alunos precisam ser constantemente estimulados para reflexão, criatividade, curiosidade, criticidade e autonomia, o que requer o oferecimento de suportes no processo de ensino e aprendizagem.

Diante desse contexto, neste artigo, evidencia-se o uso de um jogo didático, cujo aporte constitui estratégia pedagógica para o ensino de Ciências. O referido material foi apresentado aos alunos do $7^{\circ}$ ano dos anos finais do Ensino Fundamental, integrantes de uma instituição pública urbana e regular da Zona da Mata Mineira (MG), no ano de 2019. O jogo aborda a temática "Biodiversidade", com enfoque na Mata Atlântica, por ser este o bioma característico da cidade onde se localiza a escola. Os objetivos centrais deste trabalho foram a elaboração do jogo didático no intuito de favorecer uma aprendizagem significativa aos educandos referente a biodiversidade, além de refletir a potencialidade do jogo didático como proposta pedagógica no Ensino de Ciências.

Segundo Soares (2013, p. 21) “aprender pode ser uma brincadeira. Na brincadeira, podese aprender". Assim, vislumbra-se o jogo didático como uma proposta pedagógica que favorece o divertimento, bem como a construção e a ressignificação dos conhecimentos. Adicionalmente, considera-se que o mesmo recurso, ao apresentar o desafio de se encontrar 
soluções para determinados enigmas, favorece a quebra de vários obstáculos epistemológicos, diferindo-o do ensino tradicional e tecnicista.

\section{REFERENCIAL TEÓRICO}

Lima (2008) defende que o jogo é um tipo de expressão social e um meio de produção cultural dentro da sociedade. No contexto histórico da humanidade, esse entretenimento sempre estivera presente, como forma de diversão ou de competição, além de servir como instrumento que favorece a aprendizagem (CUNHA, 2012).

$\mathrm{Na}$ Roma Antiga, aponta Brougère (2003), o jogo entrelaçado em um contexto político e econômico com a chamada: "Política Pão e Circo", no qual consistia, por exemplo, em gladiadores que lutavam pela sobrevivência em uma grande arena, e claro, um contexto social fortemente marcado com o aspecto político e de poder pela população em geral. Cunha (2012) ressalta que o papel do jogo para os romanos consistia, principalmente, em formar cidadãos e garantir a formação de bons soldados para a guerra.

Já na Grécia, os jogos (também chamados de paidia) integravam o âmbito religioso, além de oferecerem princípios e ensinamentos para a educação, não se limitando apenas à infância ou a alguma fase da vida, ou seja, eram utilizados por pessoas de todas as idades (ALMEIDA, 1998). Brougère (2003) acrescenta que, na Grécia Antiga, os Jogos Olímpicos incitaram a criação de diversas modalidades esportivas, sendo realizados em homenagem aos deuses gregos.

No México, a civilização asteca desenvolvia jogos como instrumentos representativos de sua cultura, além de atribuir dimensões religiosas. Nesta dimensão acreditava que os jogos traziam a renovação do espírito e marcava um novo ciclo da vida (CUNHA, 2012). O Tlachtli, principal jogo dessa época, consistia em formar duas equipes que se enfrentavam, com a finalidade de acertar uma bola de borracha (que representava o sol) em anéis de pedras fixados nas muralhas que delimitavam a área do jogo (que por sua vez representava o universo) (SOUSTELLE, 2002).

Na Idade Média, surgem os “jogos de azar”, os quais foram severamente julgados pela Igreja Católica como uma atividade frívola, por remeterem ao vício e à destruição das relações familiares (ARIÈS, 1981; BROUGÈRE, 2003).

Sob a visão antropológica do Renascimento, a partir do século XIV, os jogos passaram por diversas mudanças e sentidos, principalmente em suas finalidades e delimitação de contextos - gradativamente, foram retiradas a reprovação e a visão negativa dos jogos, sendo 
então incorporados ao processo de formação em crianças e jovens (ARIÈS, 1981). Seguindo tal orientação, para a formação de seus alunos, as escolas jesuítas do século XVI passaram a utilizar os jogos nos ensinamentos e atividades em geral (LIMA, 2008).

Nos séculos XVII e XVIII, houve aumento na divulgação do uso do jogo como instrumento pedagógico para o processo de ensino e aprendizagem, sobretudo na área infantil, mesmo que este recurso fosse empregado como instrumento secundário no contexto educacional, como apontado por Ariès (1981).

De acordo com Huizinga (1990), os diferentes processos culturais causaram diversas interpretações dos jogos no meio social. Assim a partir da Revolução Industrial, com a produção burguesa fundada no utilitarismo e no individualismo, muitas mudanças estruturais desencadearam adaptações ao novo modelo de sociedade que se estruturava:

Os jogos turbulentos e violentos, suspeitos da tradição antiga, deram lugar à ginástica
e ao treinamento militar; o caráter coletivo e a participação comum dos membros da
sociedade são substituídos por imposições que os restringem aos grupos específicos,
considerando a idade, o gênero e a classe social (LIMA, 2008, p. 15).

No Movimento Romântico, surge a concepção do jogo com função educativa nas escolas. Ao configurar atividade indispensável na Educação Infantil, o uso desse recurso foi estendido a outras séries e modalidades de ensino, fomentando estudos e pesquisas sobre a relevância do referido instrumento pedagógico (BROUGÈRE, 2003).

Para Arantes et al. (2016), o jogo é apresentado na história como a maioria das atividades dos seres humanos, dependendo, portanto, de um contexto social para sua existência/permanência/evolução. Os mesmos autores salientam que o jogo na educação pode favorecer a motivação do aluno pela aula, tornando-a mais interessante, ao envolver o entretenimento dos estudantes e, consequentemente, tornar a aprendizagem mais dinâmica e significativa.

Do mesmo modo, Calefi e Escremim (2018) atestam que o jogo didático é uma proposta interessante de ensino, contudo, muitas vezes, seu conteúdo lúdico deve ser adaptado ao desenvolvimento das aulas, o que pode representar um grande desafio aos educadores, em decorrência de uma formação e experiência tradicionais.

Os jogos, muitas vezes, são retratados somente como um momento de recreação, ou limitados apenas às aulas de Educação Física. Segundo Arantes et al. (2006, p. 126), "jogos e brincadeiras estão presentes nas escolas, mas são excluídos das situações de ensino”.

Diante do exposto, acredita-se que o jogo pode envolver o estudante em uma aprendizagem agradável e criativa, bem como possibilitar o seu desenvolvimento, permitindo 
novas experiências e aprendizagem. É possível despertar o prazer e a alegria no próprio desafio de jogar, havendo aprendizado até por meio dos erros cometidos. Nesse sentido, o jogo enquanto ferramenta de ensino pode ser usado em diferentes momentos, tanto para apresentação de novos conteúdos como para revisão dos mesmos (ARANTES et al., 2006).

\section{Metodologia}

Como metodologia utilizada nesta pesquisa, optou-se pela abordagem qualitativa de caráter descritivo e exploratório, no intuito de permitir o contato direto e mais profundo das pesquisadoras com o objeto de estudo (OLIVEIRA, 2007).

O público-alvo é formado por 29 estudantes do $7^{\circ}$ ano dos anos finais do Ensino Fundamental, em uma escola urbana localizada na Zona Mata Mineira (MG), sendo efetuado o estudo em 2019, em duas aulas de 50 minutos, na disciplina de Ciências. Como parte experimental, foi apresentado um jogo de tabuleiro com o tema geral referente à "Biodiversidade", no qual abordaram-se conteúdos sobre a diversidade da vida e do meio ambiente, a questão ambiental da Mata Atlântica e sua preservação.

O espaço de aplicação foi a própria sala de aula e os alunos se dividiram em oito grupos. Na primeira aula, foram discutidas detalhadamente as regras do jogo e os alunos iniciaram a proposta pedagógica; a segunda aula foi destinada somente à condução do jogo.

Também foi aplicado um questionário aos participantes, antes e depois da realização do jogo, com a finalidade de analisar os conhecimentos prévios dos alunos sobre o tema, assim como as possíveis contribuições de tal proposta pedagógica. Os questionários foram constituídos com as mesmas abordagens de assuntos, apesar de terem modelos e formas de escrita diferenciadas. As perguntas foram referentes as seguintes temáticas: a importância do equilíbrio ecológico; as relações entre as devastações da natureza com a extinção de muitas espécies; a importância da preservação da Biodiversidade e a diversidade presente na Mata Atlântica. As informações obtidas foram organizadas a partir da análise descritiva (REIS; REIS, 2002), a fim de identificar as experiências oferecidas pelo jogo didático.

\section{ProduÇão E APLICAÇÃo do JOGO DIDÁTICO “GUARDiõeS DA BIODIVERSIDADE"}

A proposta do lúdico no ambiente escolar consiste em proporcionar ao educando uma educação mais interessante, que possibilite o desenvolvimento de sentidos investigativos e criativos (CRISOSTIMO; KIEL, 2017; MESSEDER, MORANDILLO, 2016). A aprendizagem em Ciências tende a ser significativa quando está em consonância aos saberes prévios dos 
educandos, de modo que os conceitos possam ser construídos continuamente, a partir de experiências/vivências históricas de cada sujeito. Sob esse viés, criou-se o jogo didático supracitado, baseado, principalmente, na questão ambiental do bioma da Mata Atlântica.

O jogo didático de tabuleiro intitulado: "Guardiões da Biodiversidade", baseado no modelo Ludo, possui a seguinte logo: "Ciência o quê?", no sentido de despertar as curiosidades dos jogadores com a indagação. O mesmo, a partir de um projeto de ensino, foi confeccionado a partir de recursos simples e acessíveis. Foi criado um "Cartão de Regras", que orienta quanto aos objetivos a serem alcançados. A seguir, na figura 1, temos as regras do jogo:

Figura 1 - Tabuleiro do jogo didático: "Guardiões da Biodiversidade"
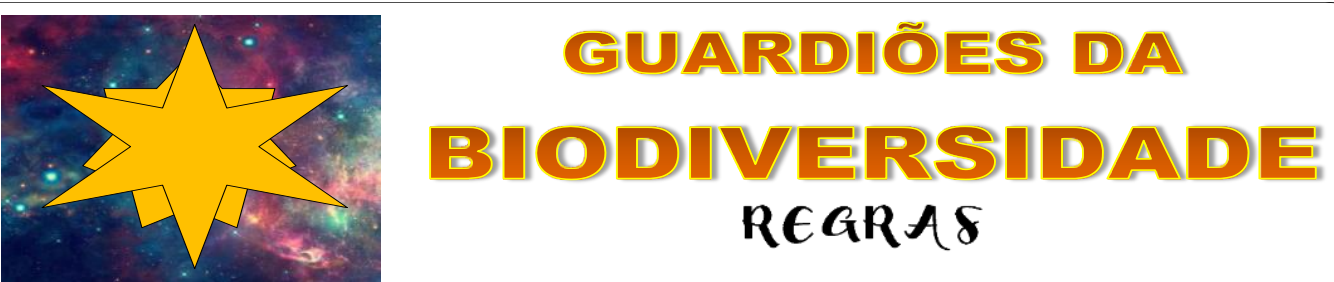

\section{Objetivo do Jogo}

Olá guardiões! Vocês sabem quantos seres vivos existem em nosso planeta? $\mathrm{Na}$ natureza, ainda não se sabe exatamente quantos seres vivos existem, no entanto estamos cercados por uma imensa biodiversidade, e todos os organismos dependem um do outro para sobreviver. Mas quando exploramos nosso planeta e destruímos ambientes naturais, colocamos em risco de extinção várias espécies, até mesmo aqueles que são ainda desconhecidas. Com isso perdemos várias riquezas naturais devido aos desiquilíbrios ambientais. Com esse jogo você irá conhecer um pouco da diversidade dos seres vivos!

\section{Tabela de Ações}

Podem participar do jogo de dois a quatro jogadores: cada jogador deve escolher um peão e a cor de sua base (vermelho, verde, amarelo e azul), sendo que cada um possui seu caminho a percorrer e ações, até levar ao centro do tabuleiro. 0 movimento das peças deve ir de acordo com o sentido das setas, e, a quantidade de casas a ser percorrida corresponde ao número tirado no dado. Se em algum momento o peão cair na casa que tenha o ponto de interrogação, o jogador deve tirar uma carta, podendo ser de um desafio; ou de perguntaresposta. 0 jogador anterior deverá realizar a leitura desta carta para que possa ser respondido à questão. Vence 0 jogador que chegar primeiro ao centro do tabuleiro.

\section{CARTAS DESAFIO}

Estas cartas possuem informações acerca de algumas espécies da fauna e da flora que estão em risco de extinção na Mata Atlântica

Desafio 1: Avance 1 casa Desafio 2: Volte 1 casa Desafio 3: Jogue outra vez jogar
Desafio 4: Tire outra carta

Desafio 5: Fique uma rodada sem jogar

Desafio 6: Escolha um jogador para ficar uma rodada sem

\section{CARTAS PERGUNTAS-RESPOSTAS}

Já nestas cartas, são variadas perguntas sobre a diversidade dos seres vivos. Ao acertar, avance uma casa; se errar, volte uma casa. Lembre-se para preservar a biodiversidade, é preciso conhecê-la. Boa sorte!

Fonte: Autorias próprias (2019). 
Cunha (2012) esclarece sobre a importância de regras claras e objetivas, como forma de diferenciar o jogo didático, no espaço escolar, dos demais jogos educativos. É válido pontuar que o jogo permite a participação de dois a quatro jogadores por vez, havendo um "peão" para cada participante, este que deve ser movimentado conforme os sentidos (setas), em posições determinadas em um percurso - a quantidade de "casas" percorridas corresponde ao número sorteado pelo dado. $\mathrm{O}$ vencedor da partida será aquele que chegar primeiro ao centro do tabuleiro. A seguir, apresenta-se o tabuleiro (Figura 2):

Figura 2 - Tabuleiro do jogo didático: "Guardiões da Biodiversidade"

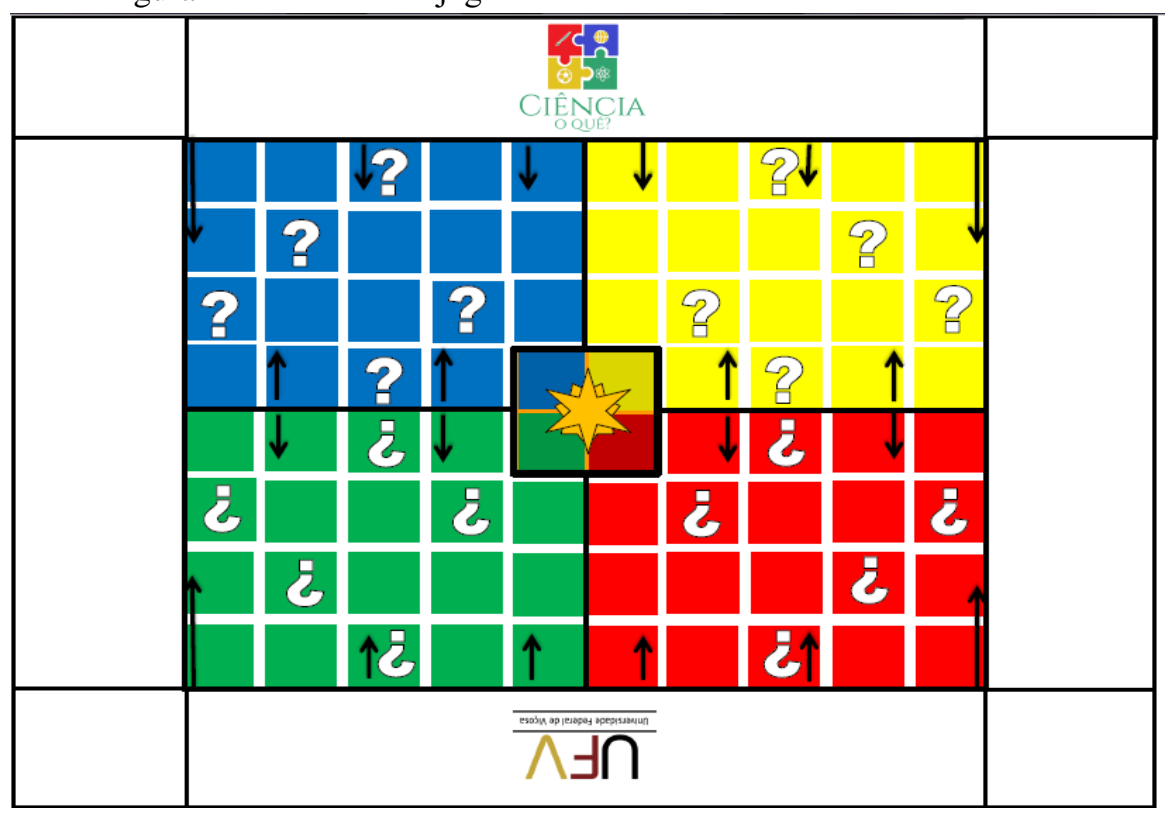

Fonte: Autorias próprias (2019).

Os peões passam pelo percurso do tabuleiro, sendo que algumas "casas" contém um ponto de interrogação, que indica uma ação dentro do jogo: pegar uma carta de uma pilha embaralhada. Essas cartas podem conter perguntas-respostas ou as cartas-desafios.

As cartas de perguntas-respostas são formadas por questões de múltipla escolha, sobre os reinos dos seres vivos, e devem ser lidas pelo jogador anterior. Se o jogador acertar, o mesmo avança uma "casa"; caso erro, deve voltar uma "casa".

A seguir, exibem-se as perguntas-respostas (Figura 3 e 4), como forma de exemplificar o conteúdo: 
Figura 3 - Carta-pergunta-resposta que se refere aos microrganismos

\begin{tabular}{|l|l|}
\hline Os microrganismos têm grande importância no solo. \\
Podemos afirmar que está incorreta: \\
A. Os microrganismos podem ser utilizados como \\
sensíveis bioindicadores na qualidade do solo. \\
B. Não tem importância, uma vez que, apenas causam \\
doenças nas plantaçôes. \\
C. Muitos microrganismos decompõem a matéria orgânica \\
e a transformam em nutrientes para o solo. \\
D. Há microrganismos que participam do ciclo do do \\
nitrogênio.
\end{tabular}

Fonte: Autorias próprias (2019).

Figura 4 - Carta-pergunta-resposta que retrata da preservação ambiental

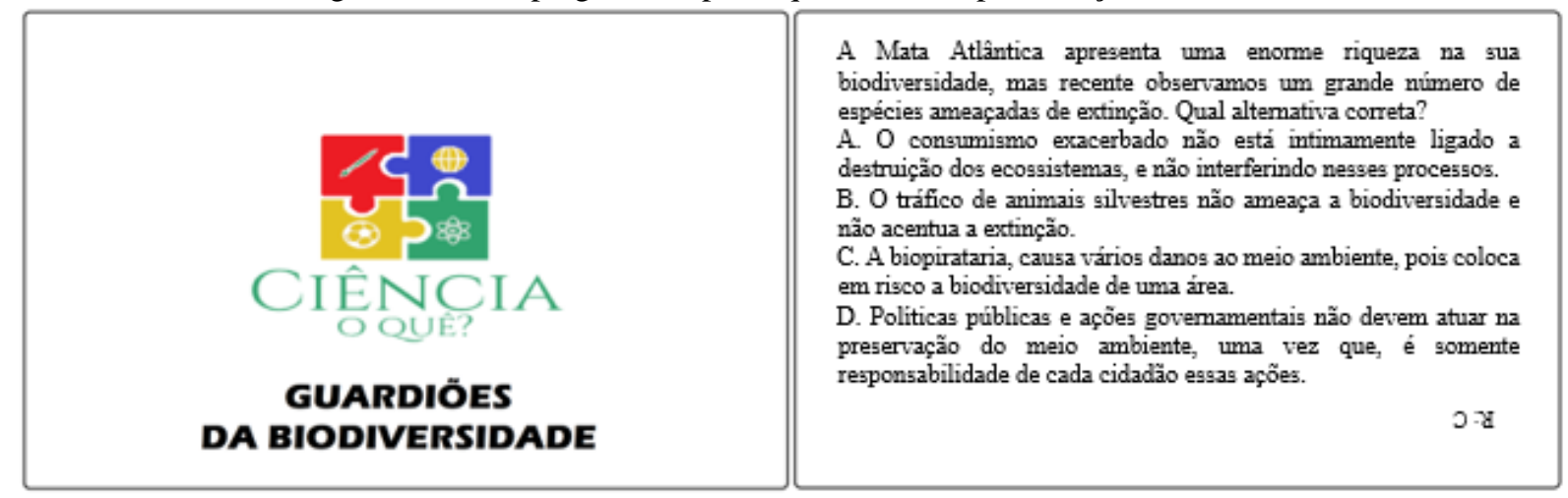

Fonte: Autoria própria (2019).

Já as cartas de desafio possuem informações acerca da fauna e da flora, trazendo informações e curiosidades. Desse modo, o jogador poderá voltar uma "casa", avançar uma "casa", ou jogar outra vez. Tais ações estão diretamente relacionadas ao nível que a espécie se encontra em extinção na natureza, no intuito de promover o respeito pelas questões ambientais. A seguir, exemplificam-se as cartas de desafio (Figuras 5 e 6 ).

Figura 5 - Carta-desafio - Espécie da fauna sob risco de extinção na Mata Atlântica

\begin{tabular}{l|l|}
\hline São felinos de médio porte que vivem em florestas \\
tropicais e, geralmente, têm hábitos noturnos. \\
Fique uma rodada \\
sem jogar \\
JAGUATIRICA \\
Leopardus pardalis
\end{tabular}

Fonte: Autorias próprias (2019). 
Figura 6 - Carta-desafio - Espécie da flora sob risco de extinção na Mata Atlântica

\begin{tabular}{|c|l|}
\hline GuARDIÖES \\
DA BIODIVERSIDADE
\end{tabular} \mid $\begin{aligned} & \text { Espécie de grande importância para Mata Atlântica, } \\
& \text { apresenta uma gama de utilidades destacam-se a utilização } \\
& \text { das sementes para artesanato, dos frutos para produção de } \\
& \text { polpa, ripas para construção e, claro o palmito, que pode } \\
& \text { ser consumido em conserva ou in natura. } \\
& \text { Avance } 1 \text { casa } \\
& \text { JUÇARA OU IÇARA } \\
& \text { Euterpe edulis }\end{aligned}$

Fonte: Autorias próprias (2019).

O jogo possui, ainda, um material de apoio, intitulado "Caderno do Professor" (Figura 6), contendo todas as respostas das questões apresentadas nas cartas. Também constam informações mais aprofundadas que docente poderá abordar durante o desenvolvimento do jogo, ou ainda em uma aula posterior.

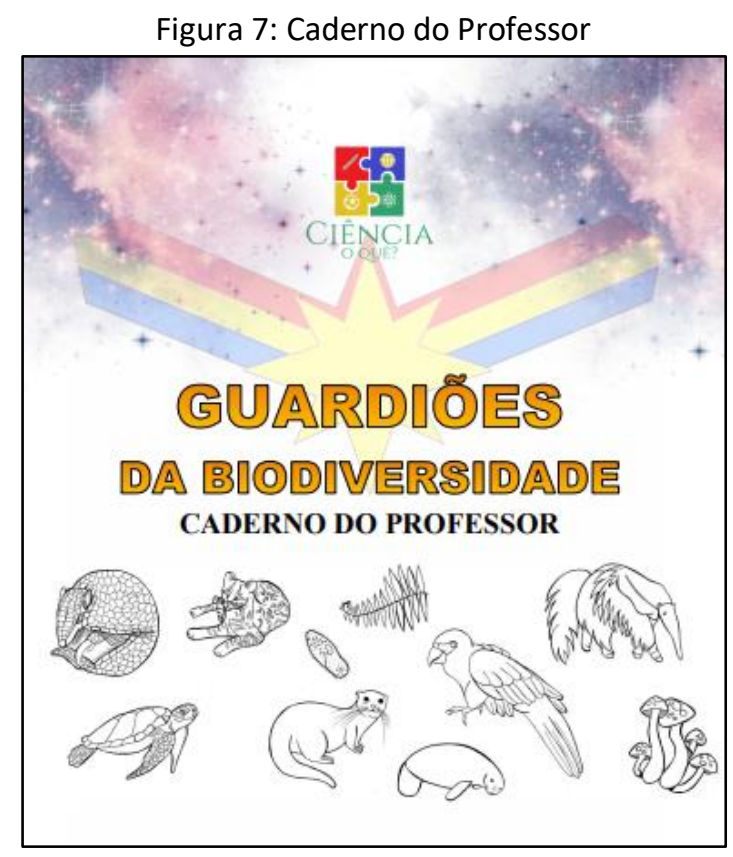

Fonte: Autorias próprias (2019).

Como forma de avaliar a proposta pedagógica aplicada foram aplicados questionários com a turma, antes e depois da aplicação do jogo didático. Ressalta-se que os participantes já haviam estudado parte do conteúdo relacionado ao jogo: o reino Monera, Protista, Fungi, e iniciado o reino Animal. Dessa forma, considera-se que o jogo constituiu um aprofundamento da disciplina, além de proporcionar uma visão geral dos conteúdos que ainda seriam apresentados.

Também é válido salientar que o detalhamento das regras foi fundamental para o desenvolvimento do jogo. Segundo Cunha (2012), o educador deve alinhar seu objetivo de 
ensino e a proposta do jogo didático desenvolvido em sala de aula, para que o jogo se torne didático, conforme o planejamento.

Na primeira questão, abordou-se a(s) consequência(s) para a vida na Terra se os fungos e bactérias deixassem de existir. Antes da aplicação do jogo didático, três estudantes não responderam, dez estudantes responderam de forma equivocada os conceitos e relações, oito estudantes responderam corretamente, mas sem dar profundidade ao tema, e oito alunos responderam corretamente, e com maior profundidade, apresentando conceitos como "decomposição" e "desequilíbrio". Após a aplicação do jogo didático, vinte alunos responderam corretamente e com profundidade e nove alunos responderam de forma incorreta a questão.

A segunda questão do questionário referiu-se à importância da preservação da Biodiversidade. Antes da aplicação do jogo didático, a pergunta continha respostas como "sim" ou "não", exigindo-se a justificativa de resposta. Das respostas, 28 marcaram "sim”, contudo, sem quaisquer justificativas. A mesma questão, posteriormente apresentada de forma discursiva, foi entregue novamente depois da aplicação do jogo, gerando os mesmos 28 discentes que confirmaram sua importância, e 21 estudantes apresentaram as justificativas, mostrando a importância ambiental e ecológica do ecossistema.

A terceira questão retratava da nomenclatura de classificação dos reinos dos seres vivos. No primeiro questionário anterior à aplicação do jogo, 12 alunos assinalaram de forma correta e, após a aplicação do jogo, o número subiu para 17. Por fim, na última questão, foi solicitado aos educandos que escrevessem as espécies que estavam em extinção. Foi observado que aumentou a diversidade de espécies depois da aplicação do jogo, tanto da fauna quanto da flora da Mata Atlântica.

Considera-se que o jogo causou divertimento e curiosidade nos educandos. Calefi e Escremin (2018) e Silva (2016) confirmam que os jogos didáticos podem despertar nos educandos diferentes formas de aprendizagem, incitando a construção da autonomia, além de estimular a imaginação, a curiosidade, o dinamismo, e consciência perante a realidade. Os mesmos relataram que ainda não haviam vivenciado essa experiência pedagógica em sala de aula. Foi observada, também, a interação com essa ferramenta pedagógica, a colaboração, cooperação e a interação educadora-educando e educando-educando. 


\section{CONSIDERAÇÕEs FINAIS}

O jogo didático "Guardiões da Biodiversidade" foi construído com a finalidade de ser um auxílio no Ensino de Ciências, proporcionando uma visão reflexiva de toda biodiversidade e de sua importância para os seres vivos. O mesmo apresenta diversas perguntas e curiosidades sobre o referido tema, voltando-se, principalmente, para a Mata Atlântica, embora possa ser adaptado de acordo com a realidade dos sujeitos envolvidos.

O bioma da Mata Atlântica, presente na região onde a escola se localiza, é reconhecido por sua riqueza biodiversa, sendo significativamente ameaçado, com diversas espécies da fauna e da flora em risco de extinção. Nessa perspectiva, objetivou-se relacionar o ensino de Ciências ao viés da preservação natural, de forma interdisciplinar, a fim de provocar pensamentos críticos sobre as ações humanas e sobre o modelo capitalista de consumo.

O ensino de Ciências deve ter estratégias didático-pedagógicas que possibilitem aos estudantes o olhar crítico e consciente sobre sua realidade. Vale ressaltar a grande importância de metodologias ativas no processo de ensino e aprendizagem, possibilitando o ensino crítico e consciente, além de alinhar os conhecimentos às várias interfaces interdisciplinares, tais como questões sociais e ambientais.

A realização do jogo apresentou resultados satisfatórios/positivos, pois foi oportunizada aos educandos uma metodologia participativa, com aprendizagem não apenas de conceitos, mas de descobertas e de coletivismo. Acreditamos que a aplicação do jogo em sala de aula deve zelar pela diversão dos estudantes, para que seja um momento onde estes brinquem e se divirtam, sem se olvidar do cunho educacional e do processo de ensino e aprendizagem.

Durante a aplicação do jogo, houve a participação colaborativa da professora regente, que já havia relatado que durante a sua formação na graduação, a partir de um ensino tradicional, não a possibilitou ter esses espaços que envolvem metodologias e propostas pedagógicas mais ativas, e que tal iniciativa em sua sala de aula iria impulsionar para a utilização de tais estratégias e recurso, perante ao entusiasmo de sua classe.

Atesta-se, assim, que o jogo didático configura alternativa viável, ao possibilitar relações de cooperação, de socialização e de troca de conhecimentos entre educador-educando e educando-educando, a partir de um ambiente estimulante para o desenvolvimento de várias habilidades cognitivas. 


\section{REFERENCIAS}

ALMEIDA, Paulo Nunes de. Educação Lúdica: Prazer de Estudar - Técnicas e jogos pedagógicos. São Paulo: Edições Loyola, 1998.

ARANTES, Valéria Amorim; MACEDO, Lino de; MACHADO, Nílson José. Jogo e projeto: Pontos e contrapontos. São Paulo: Summus, 2006.

ARIÈS, Philippe. História Social da Criança e da Família. Rio de Janeiro: Zahar, 1981.

BRASIL. Base Nacional Comum Curricular. Brasília: MEC, 2017. Disponível em: http://basenacionalcomum.mec.gov.br Acesso em: 26 de mar. de 2020.

BROUGÈRE, Gilles. Jogo e educação. Porto Alegre: Editora Artes Médicas, 2003.

CACHAPUZ, Antônio; GIL-PÉREZ, Daniel; CARVALHO, Anna Maria Pessoa de; PRAIA, João; VILCHES, Amparo. A necessária renovação do ensino das Ciências. São Paulo: Cortez, 2011.

CALEFI, Paulo Sérgio; ESCREMIN, João Vicente. Jogos, Ensino e Formação de Professores Reflexivos. Curitiba: Appris, 2018.

CARVALHO, Anna Maria Pessoa de; GIL-PÉREZ, Daniel. Formação de professores de Ciências: tendências e inovações. São Paulo: Cortez, 2011.

CHASSOT, Attico Inácio. Educação Consciência. Santa Cruz do Sul: EDUNISC, 2010.

CRISOSTIMO, Ana Lúcia; KIEL, Cristiane Aparecida. O Lúdico e o ensino de Ciências: saberes do cotidiano. Guarapuava: Ed. da Unicentro, 2017.

CUNHA, Márcia Borin. Jogos no Ensino da Química: Considerações Teóricas para sua utilização em sala de aula. Revista Química Nova na Escola, v. 34, n, 2, 2012. Disponível em: http://qnesc.sbq.org.br/online/qnesc34_2/07-PE-53-11.pdf Acesso em: 09/03/2021.

HUIZINGA, Johan. Homo ludens: O jogo como elemento da cultura. São Paulo: Perspectiva, 1990.

LIMA, José Milton. O jogo como recurso pedagógico no contexto educacional. São Paulo: Cultura Acadêmica Editora, 2008.

MESSEDER NETO, Hélio Silva; MORANDILLO, Edilson. Fortuna. O Lúdico no Ensino de Química: Considerações a partir da Psicologia Histórico-Cultural. Revista Química Nova na Escola, v. 38, n. 4, 2016. Disponível em: http://qnesc.sbq.org.br/online/qnesc38_4/11-EQF33-15.pdf. Acesso em: 09/03/2021.

OLIVEIRA, Maria Marly de. Como fazer pesquisa qualitativa. Petrópolis, RJ: Vozes, 2007.

REIS, Edna Afonso; REIS, Ilka Afonso. Análise descritiva de dados. Relatório Técnico do Departamento de Estatística da UFMG. Disponível em:

http://www.est.ufmg.br/portal/arquivos/rts/rte0202.pdf Acesso em: 09/03/2021. 
SANTOS, Wildson Luiz. Pereira. Educação científica na perspectiva do letramento como prática social: funções, princípios e desafios. Revista Brasileira de Educação, v. 12, n. 36, 2007. Disponível em: https://www.scielo.br/pdf/rbedu/v12n36/a07v1236.pdf Acesso em: 09/03/2021.

SILVA, Aline Aparecida Teixeira; CATÃO, Vinicius; SILVA, Aparecida Fátima Andrade. Análise de uma sequência didática investigativa sobre estequiometria abordando a Química dos sabões e detergentes. Revista Prática Docente, v.5, n.2, 2020. Disponível em: http://periodicos.cfs.ifmt.edu.br/periodicos/index.php/rpd/article/view/736 Acesso em: 09/03/2021.

SILVA, Andreia Santos. Circuito do Sistema Nervoso: aplicação de jogos como estratégia de aprendizagem no ensino de Biologia. Cadernos da Educação Básica, v. 1, n. 2, 2016. Disponível em: http://www.cp2.g12.br/ojs/index.php/cadernos/article/view/795 Acesso em: 09/03/2021.

SOARES, Márlon Herbert Flora Barbosa. Jogos e Atividades Lúdicas para o Ensino de Química. Goiânia: Kelps, 2013.

SOUSTELLE, Jacques. A civilização asteca. Rio de Janeiro: Jorge Zahar Ed., 2002.

XAVIER, Patrícia Maria Azevedo; FLÔR, Cristhiane Carneiro Cunha. Saberes populares e educação científica: um olhar a partir da literatura na área de ensino de ciências. Ensaio: Pesquisa em Educação em Ciências, v. 17, n. 2, 2015. Disponível em:

https://www.scielo.br/scielo.php?pid=S198321172015000200308\&script=sci abstract\&tlng= pt Acesso em: 09/03/2021. 